\title{
Application of Artificial Neural Network for Modeling and Prediction of MTT Assay on Human Lung Epithelial Cancer Cell Lines
}

Taghipour $\mathbf{M}^{1,2}$, Vand $A^{2}{ }^{2}$, Rezaei $A^{3}$ and Karim $\mathbf{G R}^{4 *}$

${ }^{1}$ Department of Biomedical Engineering, Faculty of medicine, Kermanshah University of Medical Sciences, Kermanshah, Iran

${ }^{2}$ Department of Computer Engineering, Islamic Azad University, Kermanshah, Iran

${ }^{3}$ Eelectrical Faculty, Kermanshah University of Technology, Kermanshah, Iran

${ }^{4}$ Department of Electrical Engineering, Razi University, Kermanshah, Iran

\begin{abstract}
In this paper, a three-layer artificial neural network (ANN) was investigated to predict the inhibitory concentration (IC) values assessed via MTT cell viability assay on the four types of human lung epithelial cancer cell lines. In order to achieve this purpose, a multilayer perceptron (MLP) neural network trained with back-propagation algorithm was employed for developing the ANN model. To develop the model, the input parameters were concentrations and types of cell lines and the outputs were IC10, IC20, IC 30, IC40, IC50, IC60, IC70 and IC80 values in the A549, H157, H460 and $\mathrm{H} 1975$ cell lines. The proposed ANN model has achieved good agreement with the experimental data and has a small error between the estimated and experimental values. The obtained results show that the proposed ANN model is a useful, reliable, fast and cheap tool to predict the IC values assessed via MTT cell viability assays.
\end{abstract}

Keywords: MTT assay; Artificial neural network; Multilayer perceptron; Modeling; Inhibitory concentration

Abbreviations: ANN: Artificial Neural Network; RBF: Radial Basis
Function; ANOVA: Analysis of Variance ; CF: Correlation Factor; $\mathrm{CO}_{2}$ :
Carbon Dioxide; DMSO: Dimethyl Sulfoxide; DOX: Doxorubicin; FBS:
Fetal Bovine Serum; IC: Inhibitory Concentration; IC50: Inhibitory
Concentration of 50\% Of Enzyme Activity; MAE: Mean Absolute
Error; MRE: Mean Relative Error; MTT: 3-(4:5-Dimethyl-2-Thiazol)-
2:5-Diphenyl-2H-Tetrazolium Bromide; MLP: Multilayer Perceptron;
RMSE: Root Mean Square Error; RPMI: Roswell Park Memorial
Institute Medium

\section{Introduction}

Many biological assays require the measurement of surviving and/or proliferating mammalian cells. This can be achieved by several methods, e.g., counting cells that include/exclude a dye, measuring released ${ }^{51} \mathrm{Cr}$-labeled protein after cell lysis, and measuring incorporation of radioactive nucleotides $\left(\left[{ }^{3} \mathrm{H}\right]\right.$ thymidineor $\left[{ }^{125} \mathrm{I}\right]$ iodo-deoxyuridine) during cell proliferation [1]. In 1983, a new and rapid quantitative colorimetric assay, based on the tetrazolium salt thiazolyl blue, for mammalian cell survival and cell proliferation was proposed by Mosmann [1]. At present, colorimetric assay using the tetrazolium salt thiazolyl blue, also termed MTT, after methylthiazolyl-tetrazolium [2] is widely used for assessment of cytotoxicity, cell viability and proliferation studies in cell biology [2-5]. This test is based on the cellular uptake of MTT and its subsequent reduction in the mitochondria of living cells to MTT formazan (a dark, water insoluble and blue product) [6]. The method has been extended and improved by several authors [7-10].

Doxorubicin (DOX, trade name Adriamycin) is an antitumor drug commonly used as single and in combination with other chemotherapeutic agents, for treatment of wide range of human malignancies $[11,12]$.

Flavonoids have been extensively studied for their multifaceted ability to perform as chemoprevention agents and as chemotherapeutics against a wide array of cancers $[13,14]$. Chrysin is aflavone found in the blue passion flower (Passifloracaerulea) and Honeycomb $[13,15]$.
Artificial neural network (ANN) is a highly simplified model of the biological network structure[16,17]. The basic advantage of ANN is that it does not need any mathematical model; an ANN learns from examples and recognizes patterns in a series of input and output data without any prior assumptions about their nature and interrelations [17]. Moreover, ANN is a good alternative to conventional empirical modeling based on polynomial and linear regressions [18]. Thus, ANN is a typical non-mechanistic model for modeling complex information and is known to have two intrinsic advantages. The first is its flexible capacity in apprehending the data used for training. Being intrinsically nonlinear, a trained ANN can grasp certain subtle patterns that tend to be overlooked by common statistical methods. The second advantage is its high predictive accuracy, i.e., the predictive capability for "new" data (untrained data) [19-23]. The high predictive accuracy is an assured outcome of the ability of ANN to apprehend the data [21,24,25]. On recognizing and application these advantages of ANN in MTT assays, in the current study, we report the design, training and validation of a feed-forward ANN to predict the inhibitory concentration (IC) data such that the designed ANN would (A) make sufficient use of the existing ICs data table of an available set of experimental data about chrysin enhances doxorubicin-induced cytotoxicity in human lung epithelial cancer cell lines by Brechbuhl et al. [13], (B) predict the ICs evaluated with a MTT assay in human lung epithelial cancer cell lines treated with chrysin before exposure to DOX. The predicted ICs are expected to fill the data gap for untested IC values with less waste of time and resources.

*Corresponding author: Karim GR, Department of Electrical Engineering, Razi University, Kermanshah, Iran, Tel: +98 0918237 9045; Fax: +98 831427 4623; E-mail: ghkarimi@razi.ac.ir

Received March 18, 2015; Accepted June 17, 2015; Published June 27, 2015

Citation: Taghipour M, Vand AA, Rezaei A, Karim GR (2015) Application of Artificial Neural Network for Modeling and Prediction of MTT Assay on Human Lung Epithelial Cancer Cell Lines. J Biosens Bioelectron 6: 170. doi:10.4172/21556210.1000170

Copyright: (c) 2015 Taghipour M, et al. This is an open-access article distributed under the terms of the Creative Commons Attribution License, which permits unrestricted use, distribution, and reproduction in any medium, provided the original author and source are credited. 


\section{Materials and Methods}

\section{Compiling MTT assay data for the ANN model}

Materials, cell culture and MTT assay conditions: For training the ANN model, we used experimental data evaluated by Brechbuhl [13]. The cytotoxic effects of combination drug therapy with chrysin and DOX were determined against cell lines using MTT [1]. The lung nonsmall cell epithelial cancer cell lines A549, H157, H460 and H1975 were cultured at $37^{\circ} \mathrm{C}$ with $5 \% \mathrm{CO}_{2}$ and grown in media and supplements purchased from Mediatech (Manassas, VA). All cells were grown in RPMI media containing L-glutamine and supplemented with 10\% FBS (Gemini Bio-Products, West Sacramento, CA). Cells were maintained in T-150 flasks and split into 96-well plates at least $18 \mathrm{~h}$ prior to treatment. H157 and A549 cells were seeded for treatment at 12,000 cells per well. H460 and H1975 cells were seeded for treatment at 10,000 cells per well. At the time of treatment all wells were approximately $70-75 \%$ confluent and were treated with fresh media containing the indicated compounds. After exposure, $20 \mu \mathrm{l} /$ well of MTT solution (5 $\mathrm{mg} / \mathrm{ml}$ phosphate buffered saline) was added and incubated for 3-4 h. The medium was aspirated and replaced with $150 \mu \mathrm{l} /$ well DMSO to dissolve the formazan salt. The color intensity of the formazan solution, which reflects the cell growth condition, was measured at $570 \mathrm{~nm}$ using a Spectra Max 340PC plate reader (Molecular Devices, Sunnyvale, CA).

Statistical analysis of the MTT assay data: Experimental data evaluated by Brechbuhl [13] were expressed as the mean \pm standard error of the mean (S.E.M.). All experiments included at least triplicate treatment groups and each experiment was repeated at least two times. ANOVA comparison, Tukey comparison, t-tests, linear regression curves and cytotoxicities (ICs) were calculated using Prism version 5 (GraphPad, San Diego, CA).

\section{Modeling Approach}

\section{Artificial neural network}

Artificial neural networks (ANN) is a good technique used to handle problems of modeling, prediction, control and classification [22]. An ANN is based on the operation of biological neural networks. The fundamental processing element of ANN is an artificial neuron (or simply a neuron). A biological neuron receives inputs from other sources, combines them, performs generally a nonlinear operation on the result, and then outputs the final result $[20,23,25]$. ANNs have been used in many different applications such as finance, medicine, engineering, geology and physics $[19,22,23]$. ANN eliminates the limitations of the classical approaches by extracting the desired information using the input data. Applying ANN to a system needs sufficient input and output data instead of a mathematical equation [24-27]. Multilayer perceptron (MLP) networks are the most widely used neural networks that consist of a great number of processing elements called neurons. An MLP network has one input layer, one or more hidden layer and one output layer as shown in Figure 1.

The output from $\mathrm{q}^{\text {th }}$ neuron of the first hidden layer is given by [20]:

$$
\beta_{q}=f\left(\sum_{k=1}^{p}\left(x_{k} W_{k q}\right)+b_{q}\right) \quad q=1,2, \ldots ., Q
$$

Where $x$ is the inputs, $Q$ is the number of neurons in the first hidden layer, $p$ is the number of neurons in the input layer, $b$ is the bias term, $W$ is the weighting factor and $f$ is the activation function of the first hidden layer. The output of the $\mathrm{m}^{\text {th }}$ neuron in the output layer is given by:

$$
y_{m}=\sum_{k=1}^{s}\left(\theta_{k} W_{k m}\right)+b_{m} \quad m=1,2, \ldots ., M
$$

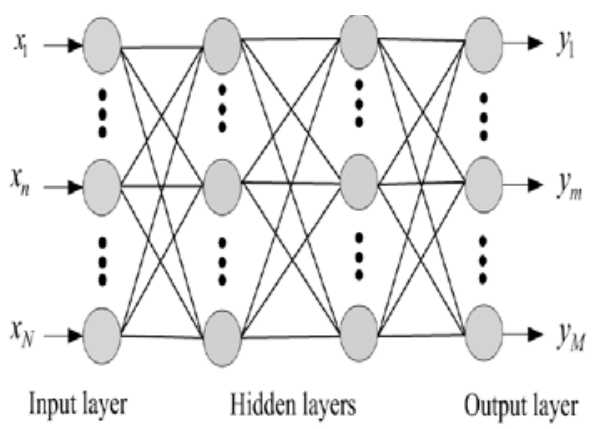

Figure 1: MLP structure.

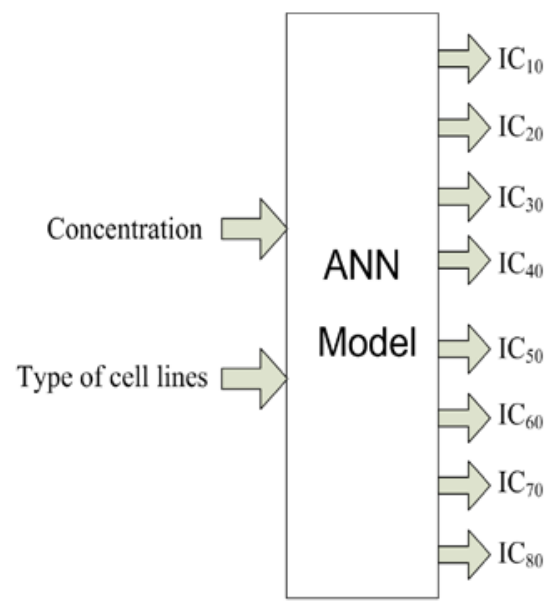

Figure 2: Simplified overview of the proposed ANN model.

Where $b$ is the bias term, $W$ is weighting factor, $s$ is the number of neurons in the second hidden layer, $M$ is the number of neurons in the output layer.

\section{Developing the model}

The simplified overview of the proposed MLP model is shown in Figure 2, where the inputs are concentrations and types of cell lines and the outputs are $\mathrm{IC}_{10}, \mathrm{IC}_{20}, \mathrm{IC}_{30}, \mathrm{IC}_{40}, \mathrm{IC}_{50}, \mathrm{IC}_{60}, \mathrm{IC}_{70}$ and $\mathrm{IC}_{80}$ values in the A549, H157, H460 and H1975 cell lines. The data set required for training the network is obtained using the experimental values [13]. For developing the ANN model, the experimental data are divided into two sets. The number of samples for training and testing are 21 (about $75 \%$ ) and 7 (about $25 \%$ ).

In this study, different ANN structures were tested and optimized to obtain the best ANN configuration. We tested many different structures with one, two, three and four hidden layers with different number of neurons in each layer also we tested Radial basis function (RBF) for prediction output. Table 1 show the comparison between these structures, where the mean relative error percentage (MRE \%) is given by:

$$
M R E \%=100 \times \frac{1}{N} \sum_{i=1}^{N}\left|\frac{X_{i}(\operatorname{Exp})-X_{i}(\operatorname{Pr} e d)}{X_{i}(\operatorname{Exp})}\right|
$$


Citation: Taghipour M, Vand AA, Rezaei A, Karim GR (2015) Application of Artificial Neural Network for Modeling and Prediction of MTT Assay on Human Lung Epithelial Cancer Cell Lines. J Biosens Bioelectron 6: 170. doi:10.4172/2155-6210.1000170

Page 3 of 6

Where $\mathrm{N}$ is the number of data and ' $X(\operatorname{Exp})$ ' and ' $X$ (Pred)' stands for experimental and predicted (ANN) values respectively.

Also we tested many ANN configurations with different structure, different training algorithm and different number of epochs. Table 2 shows the obtained MRE\% for these different ANN configurations. The best obtained ANN structure in Table 1 is the latest ANN structure in Table 2.

As it is shown in Tables 1 and 2, the MLP model with 2-11-8-98 structure (i.e., 2 neurons in the input layer, 11 neurons in the first hidden layer, 8 neurons in the second hidden layer, 9 neurons in the third hidden layer and 8 neurons in the output layer) has the least MRE\%. Therefore, we selected this structure in this paper.

\section{Results and Discussions}

Table 3 shows the specification of the proposed ANN model. The training and testing results for the proposed ANN model in comparison with experimental results [13] are shown in Tables 4 and 5 respectively.

Table 6 shows the obtained errors for the proposed ANN model, where the mean absolute error percentage (MAE \%), the root mean square error (RMSE), and the correlation factor (CF) of the proposed ANN models are calculated by:

\begin{tabular}{|c|c|c|}
\hline \multirow{2}{*}{ ANN Structure } & \multicolumn{2}{|c|}{ Average of MRE\% } \\
\cline { 2 - 3 } & Train & Test \\
\hline $2-8-11-8$ & 1.203 & 15.375 \\
\hline $2-12-10-8$ & 4.635 & 22.25 \\
\hline $2-7-8-8$ & 6.505 & 21.625 \\
\hline $2-9-8-8$ & 8.95 & 23.5 \\
\hline $2-11-8-9-8$ & $\mathbf{0 . 3 1 1}$ & $\mathbf{1 1 . 3 7 5}$ \\
\hline $2-10-8-11-8$ & 2.78 & 16.05 \\
\hline $2-7-12-7-8$ & 3.437 & 16.5 \\
\hline $2-7-10-12-8$ & 2.020 & 14.5 \\
\hline $2-9-7-11-8$ & 7.046 & 14.625 \\
\hline RBF & $1.977 e-13$ & 61.323 \\
\hline
\end{tabular}

Table 1: Average of MRE $\%$ for all outputs for different ANN structures.

$$
\begin{aligned}
& M A E \%=100 \times \frac{1}{N} \sum_{i=1}^{Z} \mid X_{i}(\text { Exp })-X_{i}(\operatorname{Pr} e d) \mid \\
& R M S E=\left[\frac{\sum_{i=1}^{N}\left(X_{i}(\text { Exp })-X_{i}(\operatorname{Pr} e d)\right)^{2}}{N}\right]^{0.5} \\
& C F=1-\left[\frac{\sum_{i=1}^{N}\left(X_{i}(\operatorname{Exp})-X_{i}(\operatorname{Pr} e d)\right)^{2}}{\sum_{i=1}^{N}\left(X_{i}(\operatorname{Exp})\right)^{2}}\right]
\end{aligned}
$$

Where $\mathrm{N}$ is the number of data and ' $X(\operatorname{Exp})$ ' and ' $X($ Pred $)$ ' stand for experimental and predicted (ANN) values respectively. Figure 3 shows the comparison between the experimental and predicted results using ANN for IC for $_{50}$ all data in A549, H157, H460 and H1975 cells.

Figure 4 shows the comparison between the experimental and predicted results using ANN for $\mathrm{IC}_{50}$ for all data in A549, H157, H460 and H1975 cell lines. The result shows that there is a good agreement between the experimental and predicted values for output parameters and the ANN model can be used as an accurate model to prediction of inhibitory concentration values accessed via MTT assay on human lung epithelial cancer cell lines co-treated with chrysin and doxorubicin.

\section{Conclusion}

In this paper, the inhibitory concentration (IC) values assessed via MTT cell viability assay on the four types of human lung epithelial cancer cell lines is modeled and predicted by artificial neural network. The proposed ANN model has achieved good agreement with the experimental data with minimum error. According to the obtained results from the ANN model and comparing them with the experimental results, it can be shown that ANN can be used in modeling and output prediction of the IC values assessed via MTT cell

\begin{tabular}{|c|c|c|c|c|c|c|c|c|c|c|c|c|}
\hline \multirow[t]{2}{*}{ Algorithm } & \multirow{2}{*}{$\begin{array}{c}\text { Number of } \\
\text { hidden layer }\end{array}$} & \multirow[t]{2}{*}{ Epoch } & \multicolumn{8}{|c|}{ The obtained MRE\% for each output (for testing data) } & \multirow{2}{*}{$\begin{array}{l}\text { Average of MRE\% } \\
\text { for all outputs } \\
\text { (for testing data) }\end{array}$} & \multirow{2}{*}{$\begin{array}{c}\text { Average of MRE\% } \\
\text { for all outputs } \\
\text { (for training data) }\end{array}$} \\
\hline & & & Ic10 & Ic20 & Ic30 & Ic40 & Ic50 & Ic60 & Ic70 & Ic80 & & \\
\hline trainbr & 2 & 400 & 27.0151 & 17.9206 & 16.7244 & 12.0143 & 13.0745407 & 13.3276 & 14.1787 & 17.6571 & 16.48 & 12.16 \\
\hline trainbr & 2 & 700 & 22.3788 & 20.0544 & 16.5557 & 15.6283 & 16.7017502 & 10.9127 & 17.2621 & 16.4354 & 16.99 & 0.3 \\
\hline trainbr & 1 & 500 & 21.048 & 16.0378 & 17.6698 & 15.5808 & 18.6307329 & 14.1561 & 20.4347 & 22.0517 & 18.2 & 10.68 \\
\hline trainbr & 1 & 1300 & 33.8414 & 21.0104 & 18.3558 & 12.529 & 15.1277031 & 18.2815 & 17.0795 & 19.6552 & 19.48 & 9.44 \\
\hline trainoss & 1 & 700 & 20.7053 & 14.4374 & 15.1151 & 13.5781 & 14.2723244 & 17.5177 & 20.7295 & 23.9746 & 17.54 & 12.59 \\
\hline trainoss & 1 & 1350 & 20.2299 & 20.2299 & 20.2299 & 20.2299 & 20.2299053 & 20.2299 & 20.2299 & 20.2299 & 20.22 & 14.21 \\
\hline trainoss & 2 & 300 & 23.0166 & 17.9729 & 18.5065 & 15.644 & 13.347814 & 12.675 & 20.2906 & 24.0792 & 18.19 & 11.08 \\
\hline trainoss & 2 & 800 & 27.17 & 24.0429 & 22.0162 & 19.1207 & 19.0589384 & 19.9404 & 16.5142 & 19.2009 & 20.88 & 14.5 \\
\hline trainrp & 1 & 800 & 22.8237 & 18.1264 & 15.4406 & 12.8661 & 13.3224577 & 9.71382 & 12.1282 & 12.817 & 14.5 & 13.74 \\
\hline trainrp & 1 & 1400 & 21.3078 & 16.2821 & 18.6634 & 17.2872 & 19.5747347 & 12.6446 & 21.9342 & 23.6726 & 18.92 & 10.46 \\
\hline trainrp & 2 & 600 & 23.183 & 19.7428 & 22.5653 & 17.6145 & 19.198957 & 9.78751 & 20.6894 & 18.6031 & 18.923 & 10.62 \\
\hline trainrp & 2 & 1000 & 36.9176 & 25.7577 & 22.384 & 16.2173 & 16.4267443 & 14.7662 & 15.7739 & 18.5915 & 20.854 & 9.47 \\
\hline trainlm & 1 & 700 & 17.5779 & 15.7346 & 16.2147 & 14.6758 & 15.2469949 & 18.1365 & 15.1962 & 15.5707 & 16.04 & 9.29 \\
\hline trainlm & 1 & 1400 & 33.8414 & 21.0104 & 18.3558 & 12.529 & 15.1277031 & 18.2815 & 17.0795 & 19.6552 & 19.48 & 9.44 \\
\hline trainlm & 2 & 600 & 35.5098 & 40.2898 & 41.9465 & 43.7499 & 40.9964492 & 37.1257 & 48.6457 & 55.9676 & 43.028 & 0.022 \\
\hline trainlm & 2 & 400 & 19.9041 & 19.6094 & 21.8283 & 21.7855 & 24.9685346 & 25.5053 & 29.3438 & 33.3467 & 24.536 & 0.45 \\
\hline trainlm & 3 & 1000 & 14.13 & 12.28 & 8.3911 & 9.562 & 7.1886 & 11.57 & 13.4965 & 14.4031 & 11.375 & 0.311 \\
\hline
\end{tabular}
viability assays. Seems that the biggest achievement of the Modeling and prediction of the inhibitory concentration values assessed via MTT

Table 2: Comparison of the ANN configurations with different training algorithm, number of hidden layers and number of epochs. 
Citation: Taghipour M, Vand AA, Rezaei A, Karim GR (2015) Application of Artificial Neural Network for Modeling and Prediction of MTT Assay on Human Lung Epithelial Cancer Cell Lines. J Biosens Bioelectron 6: 170. doi:10.4172/2155-6210.1000170

Page 4 of 6

\begin{tabular}{|l|c|}
\hline Neural network & MLP \\
\hline Number of hidden layer & 3 \\
\hline Number of neurons in the input layer & 2 \\
\hline Number of neurons in the first hidden layer & 11 \\
\hline Number of neurons in the second hidden layer & 8 \\
\hline Number of neurons in the third hidden layer & 9 \\
\hline Number of neurons in the output layer & 8 \\
\hline Learning rate & 0.5 \\
\hline Number of epochs & 1000 \\
\hline Adaption learning function & trainlm \\
\hline Activation function & tansig \\
\hline
\end{tabular}

Table 3: Comparison of the ANN configurations with different training algorithms, number of hidden layers and number of epochs.

\begin{tabular}{|c|c|c|c|c|c|c|c|c|c|c|c|c|c|c|c|c|c|}
\hline \multirow{2}{*}{$\begin{array}{l}\text { Type of } \\
\text { cell lines }\end{array}$} & \multirow[t]{2}{*}{ Concentration } & \multicolumn{8}{|c|}{ Experimental (Brechbuhl et al., 2012) } & \multicolumn{8}{|l|}{ ANN } \\
\hline & & IC10 & IC20 & IC30 & IC40 & IC50 & IC60 & IC70 & IC80 & IC10 & IC20 & IC30 & IC40 & IC50 & IC60 & IC70 & IC80 \\
\hline A549 & 0 & 0.042 & 0.093 & 0.158 & 0.245 & 0.365 & 0.543 & 0.839 & 1.43 & 0.041978 & 0.093261 & 0.157868 & 0.244424 & 0.364832 & 0.543638 & 0.838374 & 1.431309 \\
\hline A549 & 5 & 0.041 & 0.085 & 137 & 0.203 & 0.291 & 0.418 & 0.62 & 1 & 041035 & 0.084946 & 0.13698 & 0.202963 & 0.290897 & 0.417973 & 0.619953 & 1.000615 \\
\hline A549 & 10 & 0.04 & 0.081 & 0.128 & 0.187 & 0.264 & 0.374 & 0.545 & 0.864 & 0.040075 & 0.080859 & 0.128033 & 0.186818 & 0.263701 & 0.3739 & 0.546035 & 0.864042 \\
\hline A549 & 20 & 0.029 & 0.061 & 0.099 & 0.147 & 0.212 & 0.306 & 0.456 & 0.742 & 0.028952 & 0.060985 & 0.09902 & 0.147473 & 0.211931 & 0.306434 & 0.455652 & 0.740717 \\
\hline A549 & 25 & 0.018 & 0.046 & 0.085 & 0.14 & 0.223 & 0.354 & 0.587 & 1.087 & 0.018011 & 0.046008 & 0.084982 & 0.139996 & 0.222723 & 0.353856 & 0.587 & 1.088188 \\
\hline A549 & 30 & 0.017 & 0.045 & 086 & 0.146 & 238 & 0.388 & 0.661 & 1.267 & 0.016991 & 0.045034 & 0.085969 & 0.145809 & 0.238652 & 0.387638 & 0.661005 & 1.266474 \\
\hline H157 & 5 & 0.075 & 0.135 & 199 & 0.274 & 367 & 0.492 & 0.678 & 1 & 0.074995 & 0.134953 & 0.199222 & 0.274026 & 0.366762 & 0.491727 & 0.677891 & 1.000537 \\
\hline $\mathrm{H} 157$ & 10 & 0.095 & 0.153 & 0.212 & 0.275 & 0.35 & 0.446 & 0.581 & 0.801 & 0.094935 & 0.15301 & 0.212266 & 0.274863 & 0.350125 & 0.446003 & 0.58088 & 0.800786 \\
\hline H157 & 15 & 0.072 & 0.124 & 0.179 & 0.241 & 0.317 & 0.417 & 0.562 & 0.809 & 0.072014 & 0.123935 & 0.178989 & 0.241067 & 0.317033 & 0.417155 & 0.561825 & 0.808929 \\
\hline $\mathrm{H} 157$ & 25 & 0.062 & 0.114 & 0.171 & 0.239 & 0.325 & 0.442 & 0.671 & 0.928 & 0.061993 & 0.11399 & 0.171019 & 0.238955 & 0.325174 & 0.441993 & 0.670977 & 0.927794 \\
\hline H157 & 30 & 0.075 & 0.132 & 0.193 & 0.264 & 0.351 & 0.467 & 0.638 & 0.932 & 0.075 & 0.131999 & 0.192638 & 0.264524 & 0.351302 & 0.466654 & 0.638305 & 0.931391 \\
\hline $\mathrm{H} 460$ & 0 & 0.012 & 0.022 & 0.034 & 0.049 & 0.067 & 0.042 & 0.133 & 0.205 & 0.011998 & 0.021983 & 0.034004 & 0.049047 & 0.067017 & 0.042005 & 0.133019 & 0.204852 \\
\hline $\mathrm{H} 460$ & 10 & 0.011 & 0.017 & 0.023 & 0.028 & 0.035 & 0.039 & 0.053 & 0.07 & 0.011 & 0.01701 & 0.023007 & 0.02797 & 0.034991 & 0.038998 & 0.052994 & 0.070043 \\
\hline $\mathrm{H} 460$ & 15 & 0.013 & 0.017 & 0.021 & 0.025 & 0.03 & 0.02 & 0.042 & 0.051 & 0.013006 & 0.017006 & 0.020991 & 0.025007 & 0.029951 & 0.019998 & 0.042003 & 0.05104 \\
\hline $\mathrm{H} 460$ & 20 & 0.014 & 0.02 & 0.024 & 0.029 & 0.033 & 0.02 & 0.046 & 0.056 & 0.013996 & 0.020009 & 0.024003 & 0.028968 & 0.033037 & 0.019999 & 0.045991 & 0.056002 \\
\hline $\mathrm{H} 460$ & 30 & 0.003 & 0.006 & 0.008 & 0.011 & 0.015 & 0.02 & 0.027 & 0.039 & 0.003 & 0.005999 & 0.008001 & 0.011002 & 0.015005 & 0.020001 & 0.027 & 0.038988 \\
\hline H1975 & 0 & 0.014 & 0.025 & 0.036 & 0.05 & 0.066 & 0.087 & 0.119 & 0.173 & 0.014 & 0.024941 & 0.036074 & 0.050112 & 0.065883 & 0.087021 & 0.118999 & 0.172921 \\
\hline H1975 & 5 & 0.018 & 0.024 & 0.03 & 0.036 & 0.042 & 0.049 & 0.058 & 0.072 & 0.017998 & 0.024027 & 0.029924 & 0.035995 & 0.042096 & 0.048992 & 0.058014 & 0.071943 \\
\hline H1975 & 15 & 0.013 & 0.017 & 0.021 & 0.024 & 0.028 & 0.033 & 0.038 & 0.047 & 0.012995 & 0.016948 & 0.020973 & 0.024123 & 0.028047 & 0.033006 & 0.038029 & 0.046846 \\
\hline H1975 & 20 & 0.013 & 0.019 & 0.024 & 0.029 & 0.034 & 0.041 & 0.05 & 0.063 & 0.013008 & 0.019028 & 0.023958 & 0.028992 & 0.033963 & 0.040999 & 0.050002 & 0.063069 \\
\hline H1975 & 30 & 0.015 & 0.02 & 0.025 & 0.03 & 0.035 & 0.041 & 0.049 & 0.061 & 0.014999 & 0.020046 & 0.025096 & 0.029813 & 0.034954 & 0.040992 & 0.048949 & 0.061195 \\
\hline
\end{tabular}
Table 4: Specification of the best proposed ANN model.

\begin{tabular}{|c|c|c|c|c|c|c|c|c|c|c|c|c|c|c|c|c|c|}
\hline \multirow{2}{*}{$\begin{array}{l}\text { Type of } \\
\text { cell lines }\end{array}$} & \multirow[t]{2}{*}{ Concentration } & \multicolumn{8}{|c|}{ Experimental (Brechbuhl et al., 2012) } & \multicolumn{8}{|c|}{ ANN } \\
\hline & & IC10 & IC20 & IC30 & IC40 & IC50 & IC60 & IC70 & IC80 & IC10 & IC20 & IC30 & IC40 & IC50 & IC60 & IC70 & IC80 \\
\hline A549 & 15 & 0.031 & 0.062 & 0.1 & 0.147 & 0.21 & 0.3 & 0.441 & 0.707 & 0.028841 & 0.061222 & 0.099951 & 0.14958 & 0.215928 & 0.313467 & 0.467635 & 0.7657 \\
\hline $\mathrm{H} 157$ & 0 & 065 & 0.147 & 0.253 & 0.393 & 0.589 & 0.884 & 1.38 & 2.36 & 0.082 & 0.158206 & 0.24 & 0.350962 & 0.49 & 0.67 & 0.96 & 2.219227 \\
\hline $\mathrm{H} 157$ & 20 & 0.091 & 0.15 & 0.209 & 0.247 & 0.351 & 0.451 & 0.591 & 0.823 & 0.068937 & 0.123067 & 0.181563 & 0.250181 & 0.335246 & 0.449087 & 0.633137 & 0.91099 \\
\hline $\mathrm{H} 460$ & 5 & 0.01 & 0.016 & 0.021 & 0.026 & 0.033 & 0.035 & 0.052 & 0.07 & 0.008354 & 0.009992 & 0.016618 & 0.019554 & 0.030154 & 0.027742 & 0.055977 & 0.071152 \\
\hline $\mathrm{H} 460$ & 25 & 0.004 & 0.007 & 0.009 & 0.013 & 016 & 0.02 & 0.026 & 036 & 0.0 & 0. & 0 & 0. & 0. & 0. & 423 & 216 \\
\hline H1975 & 10 & 0.017 & 0.023 & 0.029 & 0.035 & 0.042 & 0.05 & 0.06 & 0.076 & 0.015019 & 0.019366 & 0.023818 & 0.027586 & 0.031505 & 0.032587 & 0.041633 & 0.051344 \\
\hline H1975 & 25 & 0.014 & 0.019 & 0.024 & 0.028 & 0.034 & 0.04 & 0.047 & 0.059 & 0.013679 & 0.019547 & 0.024476 & 0.029507 & 0.034269 & 0.039141 & 0.049207 & 0.062233 \\
\hline
\end{tabular}

Table 5: The Comparison between experimental and predicted ANN results for training data.

assay using artificial neural network that was conducted in this paper is create a newer, faster and more efficient method with a very low cost and with high accuracy. The development of this method can be allows finding the optimal drug concentrations on different cell lines using computational intelligence modeling without repeating them in vitro.

\section{Acknowledgement}

This article was extracted from the thesis prepared by Mostafa Taghipour to fulfill the requirements required for earning the master's degree. The authors thank the Department of Biomedical Engineering, Kermanshah University of medical sciences.

\section{Authors' Contributions}

Designing the method of study; collection, validation of the data: Mostafa Taghipour, Abbas Rezaei, analysis of the data; drafting the manuscript and final revision: Ayoub Adineh Vand. Validation and analysis of the data and final revision: 
Citation: Taghipour M, Vand AA, Rezaei A, Karim GR (2015) Application of Artificial Neural Network for Modeling and Prediction of MTT Assay on Human Lung Epithelial Cancer Cell Lines. J Biosens Bioelectron 6: 170. doi:10.4172/2155-6210.1000170

Page 5 of 6

\begin{tabular}{|l|c|c|c|c|c|c|}
\hline \multirow{2}{*}{ Output } & \multicolumn{2}{|c|}{ MAE } & \multicolumn{2}{c|}{ RMSE } & \multicolumn{2}{c|}{ CF } \\
\cline { 2 - 7 } & Train & Test & Train & Test & Train & Test \\
\hline IC10 & $1.52 \mathrm{E}-05$ & 0.006638 & $2.62 \mathrm{E}-05$ & 0.010782 & 0.999999 & 0.935947 \\
\hline IC20 & $4.28 \mathrm{E}-05$ & 0.007065 & $7.21 \mathrm{E}-05$ & 0.011347 & 0.999999 & 0.98275 \\
\hline IC30 & $7.02 \mathrm{E}-05$ & 0.006433 & 0.000119 & 0.011026 & 0.999999 & 0.996787 \\
\hline IC40 & 0.000134 & 0.009188 & 0.000218 & 0.016406 & 0.999998 & 0.996212 \\
\hline IC50 & 0.000138 & 0.019186 & 0.000203 & 0.038126 & 0.999999 & 0.994751 \\
\hline IC60 & 0.000121 & 0.035157 & 0.000216 & 0.077989 & 0.999999 & 0.9862 \\
\hline IC70 & 0.000139 & 0.072462 & 0.000288 & 0.157204 & 0.999999 & 0.971827 \\
\hline IC80 & 0.000352 & 0.145674 & 0.000547 & 0.320428 & 0.999999 & 0.960799 \\
\hline
\end{tabular}

Table 6: The Comparison between experimental and predicted ANN results for testing data.
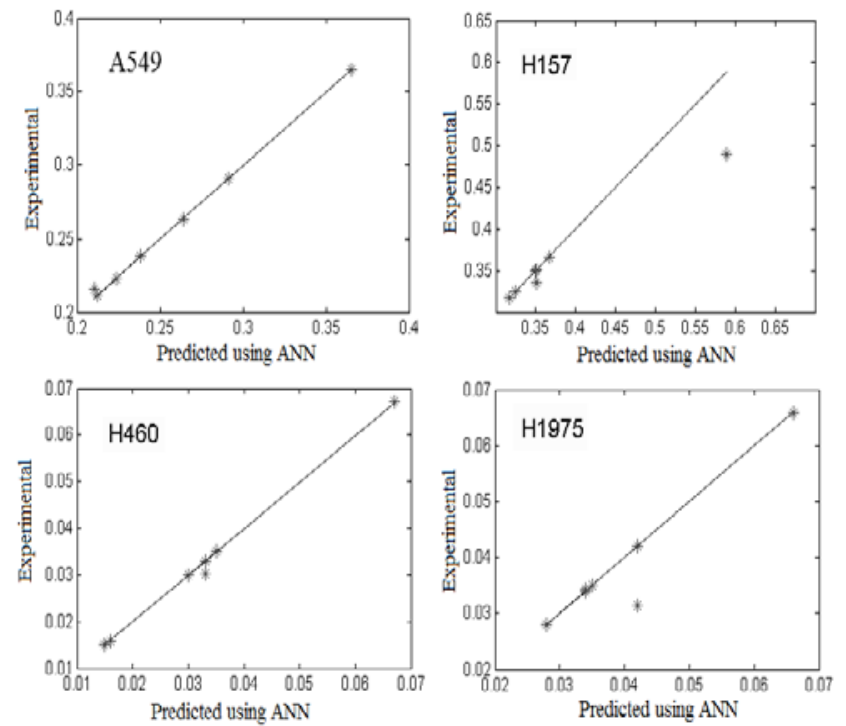

Figure 3: Comparison with the experimental for $\mathrm{IC}_{50}$ in $\mathrm{A} 549, \mathrm{H} 157, \mathrm{H} 460$ and H1975 cells.
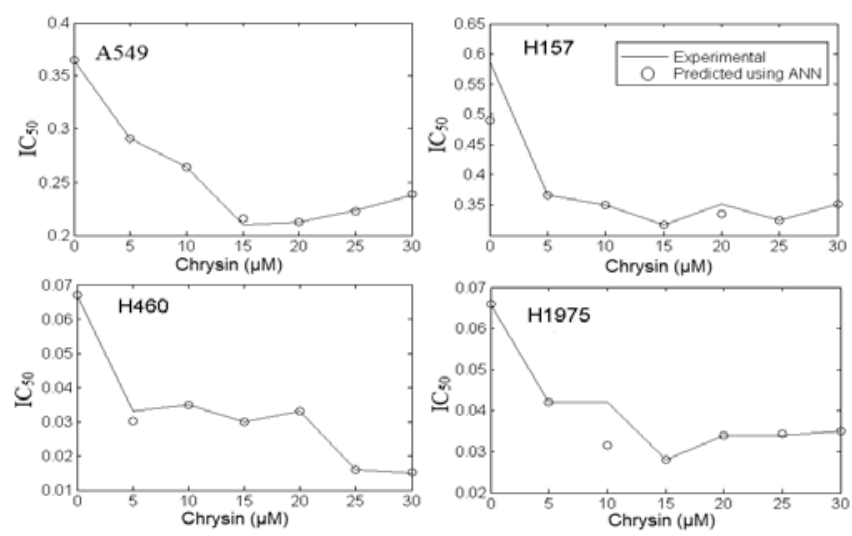

Figure 4: Comparison of the $\mathrm{ANN}$ and experimental results for $\mathrm{IC}_{50}$ as a function of Chrysin on DOX -induced cytotoxicity in A549, H157, H460 and H1975 cell lines.

G.H.Karimi, The authors declare their sincere gratification to the family and friends for their huge support during the time spent on this article.

\section{References}

1. Mosmann T (1983) Rapid colorimetric assay for cellular growth and survival: application to proliferation and cytotoxicity assays. J Immunol Methods 65: 55-63.

2. Stockert JC, Blázquez-Castro A, Cañete M, Horobin RW, Villanueva A (2012) MTT assay for cell viability: Intracellular localization of the formazan product is in lipid droplets. Acta Histochem 114: 785-796.

3. Kiernan JA (2001) Classification and naming of dyes, stains and fluorochromes. Biotech Histochem 76: 261-278.

4. Berridge MV, Herst PM, Tan AS (2005) Tetrazolium dyes as tools in cell biology: new insights into their cellular reduction. Biotechnol Annu Rev 11: 127-152.

5. van Meerloo J, Kaspers GJ, Cloos J (2011) Cell sensitivity assays: the MTT assay. Methods Mol Biol 731: 237-245.

6. Tan F, Wang M, Wang W, Lu Y (2008) Comparative evaluation of the cytotoxicity sensitivity of six fish cell lines to four heavy metals in vitro. Toxicol In Vitro 22: 164-170

7. Carmichael J, DeGraff WG, Gazdar AF, Minna JD, Mitchell JB (1987) Evaluation of a tetrazolium-based semiautomated colorimetric assay: assessment of chemosensitivity testing. Cancer Res 47: 936-942.

8. Chiba K, Kawakami K, Tohyama K (1998) Simultaneous evaluation of cell viability by neutral red, MTT and crystal violet staining assays of the same cells. Toxicol In Vitro 12: 251-258.

9. Denizot F, Lang R (1986) Rapid colorimetric assay for cell growth and survival. Modifications to the tetrazolium dye procedure giving improved sensitivity and reliability. J Immunol Methods 89: 271-277.

10. Gerlier D, Thomasset N (1986) Use of MTT colorimetric assay to measure cell activation. J Immunol Methods 94: 57-63.

11. BogdanoviÄ G, KojiÄ V, Dordevi A, Canadanovi-Brunet J, Vojinovi-Miloradov $M$, et al. (2004) Modulating activity of fullerol $\mathrm{C} 60(\mathrm{OH}) 22$ on doxorubicininduced cytotoxicity. Toxicol In Vitro 18: 629-637.

12. Stewart CF, Ratain MJ (2001) Pharmacology of cancer chemotherapy, topoisomerase interactive agents, Lippincott Williams and Wilkins, Philadelphia.

13. Brechbuhl HM, Kachadourian R, Min E, Chan D, Day BJ (2012) Chrysin enhances doxorubicin-induced cytotoxicity in human lung epithelial cancer cell lines: the role of glutathione. Toxicol Appl Pharmacol 258: 1-9.

14. Ramos S (2008) Cancer chemoprevention and chemotherapy: dietary polyphenols and signalling pathways. Mol Nutr Food Res 52: 507-526.

15. Walle UK1, Galijatovic A, Walle T (1999) Transport of the flavonoid chrysin and its conjugated metabolites by the human intestinal cell line Caco-2. Biochem Pharmacol 58: 431-438.

16. Khajeh M, Moghaddam MG, Shakeri M (2012) Application of artificial neura network in predicting the extraction yield of essential oils of Diplotaenia cachrydifolia by supercritical fluid extraction. The Journal of Supercritical Fluids 69: 91-6.

17. Mandal S, Sivaprasad PV, Venugopal S, Murthy KPN (2009) Artificial neura network modeling to evaluate and predict the deformation behavior of stainless steel type AISI 304L during hot torsion. Applied Soft Computing 9: 237-244.

18. Kose E (2008) Modelling of colour perception of different age groups using artificial neural networks. Expert Systems with Applications An International Journal archive 34: 2129-2139.

19. Dehlaghi V, Taghipour M, Haghparast A, Roshani GH, Rezaei A, et al. (2015) Prediction of the thickness of the compensator filter in radiation therapy using computational intelligence. Medical Dosimetry 40: 53-57.

20. Hornik K, Stinchcombe M, White H (1989) Multilayer feedforward networks are universal approximators. Neural Networks 2: 359-366.

21. Hornik K (1991) Approximation capabilities of multilayer feedforward networks. Neural Networks 4: 251-257.

22. Mahtab M, Taghipour M, Roshani G, Habibi M (2014) Approach to the Highest HXR Yield in Plasma Focus Device Using Adaptive Neurofuzzy Inference System to Optimize Anode Configuration. Journal of Experimental Physics.

23. Salehizadeh A, Taghipour M, Nazemi E, Roshani GH, Amir S, et al. (2014) Prediction of Optimum Design of Anode Shape for Obtaining Highest Soft 
Citation: Taghipour M, Vand AA, Rezaei A, Karim GR (2015) Application of Artificial Neural Network for Modeling and Prediction of MTT Assay on Human Lung Epithelial Cancer Cell Lines. J Biosens Bioelectron 6: 170. doi:10.4172/2155-6210.1000170

Page 6 of 6

X-Ray Yield in plasma Focus Device Using Adaptive Neuro-Fuzzy Inference System.

24. Adineh-Vand A, Torabi M, Roshani G, Taghipour M, Feghhi S, et al. (2014) Application of Adaptive Neuro-Fuzzy Inference System for Prediction of Neutron Yield of IR-IECF Facility in High Voltages. Journal of Fusion Energy 33: $13-9$

25. Meng $Y$, Lin BL (2008) A feed-forward artificial neural network for prediction of the aquatic ecotoxicity of alcohol ethoxylate. Ecotoxicol Environ Saf 71 : 172-186.

26. Taylor JG (1996) Neural networks and their applications, John Wiley and Sons Ltd, West Sussex, United kingdom.

27. Bas D, Boyaci IH (2007) Modeling and optimization II: Comparison of estimation capabilities of response surface methodology with artificial neural networks in a biochemical reaction. Journal of Food Engineering 78: 846-854. 